\title{
BMJ Global Health Immediate postnatal care following childbirth in Ugandan health facilities: an analysis of Demographic and Health Surveys between 2001 and 2016
}

\author{
Teesta Dey (D , ${ }^{1}$ Sam Ononge, ${ }^{2}$ Andrew Weeks, ${ }^{1}$ Lenka Benova ${ }^{3}$
}

To cite: Dey T, Ononge S, Weeks A, et al. Immediate postnatal care following childbirth in Ugandan health facilities: an analysis of Demographic and Health Surveys between 2001 and 2016. BMJ Global Health 2021;6:e004230. doi:10.1136/ bmjgh-2020-004230

Handling editor Sanni Yaya

- Additional supplemental material is published online only. To view, please visit the journal online (http://dx.doi.org/10. 1136/bmjgh-2020-004230)

Received 23 October 2020 Revised 27 March 2021 Accepted 30 March 2021
Check for updates

(C) Author(s) (or their employer(s)) 2021. Re-use permitted under CC BY. Published by BMJ.

${ }^{1}$ Women's and Children's Health, University of Liverpool, Liverpool, UK

${ }^{2}$ Department of Obstetrics and Gynaecology, Makerere University, Kampala, Uganda ${ }^{3}$ Department of Public Health, Institute of Tropical Medicine, Antwerpen, Belgium

Correspondence to Dr Teesta Dey; teesta.dey@liverpool.ac.uk

\section{ABSTRACT}

Introduction Progress in reducing maternal and neonatal mortality, particularly in sub-Saharan Africa, is insufficient to achieve the Sustainable Developmental Goals by 2030. The first 24 hours following childbirth (immediate postnatal period), where the majority of morbidity and mortality occurs, is critical for mothers and babies. In Uganda, $<50 \%$ of women reported receiving such care. This paper describes the coverage, changes over time and determinants of immediate postnatal care in Uganda after facility births between 2001 and 2016.

Methods We analysed the 2006, 2011 and 2016 Ugandan Demographic and Health Surveys, including women 15-49 years with most recent live birth in a healthcare facility during the survey 5 -year recall period. Immediate postnatal care coverage and changes over time were presented descriptively. Multivariable logistic regression was used to examine determinants of immediate postnatal care.

Results Data from 12872 mothers were analysed. Between 2006 and 2016, births in healthcare facilities increased from $44.6 \%(95 \%$ Cl: $41.9 \%$ to $47.3 \%$ ) to $75.2 \%$ (95\% Cl: $73.4 \%$ to $77.0 \%$ ) and coverage of immediate maternal postnatal care from $35.7 \%$ (95\% Cl $33.4 \%$ to $38.1 \%$ ) to $65.0 \%(95 \%$ Cl: $63.2 \%$ to $66.7 \%)$. The majority of first checks occurred between 1 and 4 hours post partum; the median time reduced from 4 hours to 1 hour. The most important factor associated with receipt of immediate postnatal care was women having a caesarean section birth adjusted OR (aOR) 2.93 (95\% Cl: 2.28 to 3.75$)$. Other significant factors included exposure to mass media aOR 1.38 (95\% Cl: 1.15 to 1.65$)$, baby being weighed at birth aOR 1.84 (95\% Cl: 1.58 to 2.14) and receipt of antenatal care with 4+Antenatal visits aOR 2.34 (95\% Cl: 1.50 to 3.64). Conclusion In Uganda, a large gap in coverage remains and universal immediate postnatal care has not materialised through increasing facility-based births or longer length of stay. To ensure universal coverage of highquality care during this critical time, we recommend that maternal and newborn services should be integrated and actively involve mothers and their partners.

\section{INTRODUCTION}

Globally, since 2000, maternal and neonatal mortality rates have declined significantly and rates are currently 211 per 100000 live births and 18 per 1000 live births, respectively. ${ }^{12}$
Key questions

What is already known?

- Postnatal care has the poorest coverage levels in the obstetric continuum of care.

- The highest maternal and newborn morbidity and mortality occurs in the immediate postnatal period (within 24 hours of birth)

What are the new findings?

- Although there are increases in the proportion of births occurring in health facilities, and immediate postnatal care coverage after facility birth has doubled, coverage remains suboptimal over the time period examined.

- In facility births, the timing of the first postnatal check has shifted closer to the time of birth.

- Women/newborns with complications and those with higher social status are more likely to report receiving immediate postnatal checks.

What do the new findings imply?

- There is need to improve the coverage of immediate postnatal care checks

- It is important to establish guidance on the optimal timing for postnatal maternal checks.

- New strategies are needed to increase coverage of high-quality postnatal care, for example, integration of maternal and newborn care services, or active involvement of mothers and birth partners.

Although encouraging, this progress is insufficient to achieve the Sustainable Development Goals of 70 maternal deaths per 100000 live births and 12 neonatal deaths per 1000 live births by 2030. Moreover, the majority of countries failing to reach these levels are in sub-Saharan Africa. ${ }^{34}$ Over the last 10 years, work has been done to improve the continuum of care provided to mothers before and during childbirth through increasing regular, skilled antenatal clinic provision and facility-based deliveries. This may have contributed to the steady decline of 
maternal and neonatal mortality rates. ${ }^{56}$ However, postnatal care is often neglected and overlooked. ${ }^{78}$

Most maternal and newborn mortality occurs between the time of birth and the first 2 days post partum, and a focus on the immediate postnatal period is therefore important. ${ }^{910}$ Key causes of maternal mortality include postpartum haemorrhage, hypertensive disorders, preeclampsia and sepsis. ${ }^{11}$ Key causes of newborn mortality include preterm birth complications, infection and intrapartum conditions such as asphyxia. ${ }^{12}$ The vast majority of cases of maternal and newborn mortality are treatable and preventable but require quick recognition and good-quality care..$^{13} 14$ As such, there has been a push to increase the number of women delivering in healthcare facilities in low-resource settings in the hope that this will help increase coverage of care during birth and the ongoing postpartum period. ${ }^{14}$ Postnatal care is care provided to both mother and baby following childbirth, and is recommended to continue regularly for 6 weeks. ${ }^{15}$ Immediate postnatal care is the initial care provided by trained health workers to women in the first 24 hours following birth of baby and can be provided at home or within a health facility depending on place of birth. It is a critical time period in childbirth where maternal and newborn mortality and morbidity is the highest, particularly in sub-Saharan Africa. ${ }^{911}$

Postnatal care for a newborn baby involves ensuring good feeding, assessing vital signs, examining the umbilical stump and checking for sepsis and jaundice. For mothers, these checks involve measuring vital signs, assessing and addressing any physical symptoms that the mother is experiencing which may indicate severe conditions, assessing uterine contraction, vaginal tears/ discharge or caesarean incision sites, assessing their ability to urinate and defecate, screening for postnatal depression and conducting any other assessments based on existing conditions. Conducting this care is pertinent as it not only allows these assessments to occur and any treatment to be initiated, if needed, but provides an opportunity for health workers to provide advice and counselling on breastfeeding and newborn care. For facility-based births, WHO has advised that for at least 24 hours following vaginal delivery, women should be observed and cared for in the facility where they gave birth, to enable mothers and babies to receive this vital care. ${ }^{15}$ For home births, the first postnatal check should occur within 24 hours of birth. Thereafter, all mothers and newborns should receive at least three additional postnatal checks on day 3 , between day 7 and 14 , and between week 2 and week 6 following birth of baby. ${ }^{15}$

Despite the increase in healthcare facility births, in many low resource settings $>75 \%$ of mothers do not receive the adequate postnatal health checks they require ${ }^{1617}$ In Uganda, over the past 30 years, there has been a considerable shift in the health system arrangements. In the early 1990s, Uganda implemented a widescale public sector reform in line with the World Banks Structural Adjustment programme. ${ }^{18}$ This resulted in a widescale downsizing and decentralising of health services increasing access. Public health services are free allowing more women to access care. ${ }^{19}$ Additionally, strong political will, donor funding and a rise in non-profit facilities have been highlighted as key contributors to resource mobilisation maternal health prioritisation..$^{20}{ }^{21}$ As such, promising progress has been made to improve the percentage of births occurring in health facilities, from $37 \%$ in 2000 to $73 \%$ in $2016 .^{5}$ This has coincided with a $30 \%$ decline in maternal mortality rates since $1988 .{ }^{5}$ However, despite these efforts, the maternal mortality rate in 2017 remained high at 336/100 000 live births and adequate postnatal care remains the poorest performing aspect of the obstetric continuum in Uganda. ${ }^{5}$ National guidance from the Ugandan Ministry of Health for postnatal care exists within the Uganda Clinical Guideline which were created adopting WHO recommendations. ${ }^{22}$ However, most recent estimates indicate that the provision of this vital care occurred in less than $50 \%$ of facility births making it the fifth worst performing country out of the 33 sub-Saharan African countries examined.$^{17}$ It is clear that change is needed to enable equity in coverage of postnatal care.

Existing global research has often focused on postnatal care coverage among rural and home-based births or all births and there is little literature specific to care following facility births in Uganda. ${ }^{23-25}$ Additionally, the intersection between maternal and newborn postnatal care coverage has not been described in previous work. Given the lack of improvement to postnatal care coverage from healthcare facility births despite the large shift toward facility-based childbirth, we sought to understand the coverage, changes over time and determinants of immediate postnatal care in Uganda after facility births over the past 15 years.

In this manuscript, we look to describe the coverage and timing of immediate postnatal care for mothers following childbirth in healthcare facilities in Uganda using three Ugandan Demographic Health Surveys (2006, 2011, 2016). Additionally, we analysed the determinants of immediate maternal postnatal care following deliveries in healthcare facilities on the 2016 survey.

\section{METHODS \\ Data}

Household surveys are the main source of data used within maternal health to compare coverage trends and inequalities both within and between countries. ${ }^{26}$ The Demographic and Health Surveys (DHS) are crosssectional nationally representative household surveys, usually covering 5000-30 000 households. They collect data from women in reproductive age (15-49 years) about births and the use of reproductive and maternal care. We used the DHS collected in Uganda in 2006, 2011 and 2016. The DHS use a multilevel cluster sampling survey design; individual women's survey weights, and 


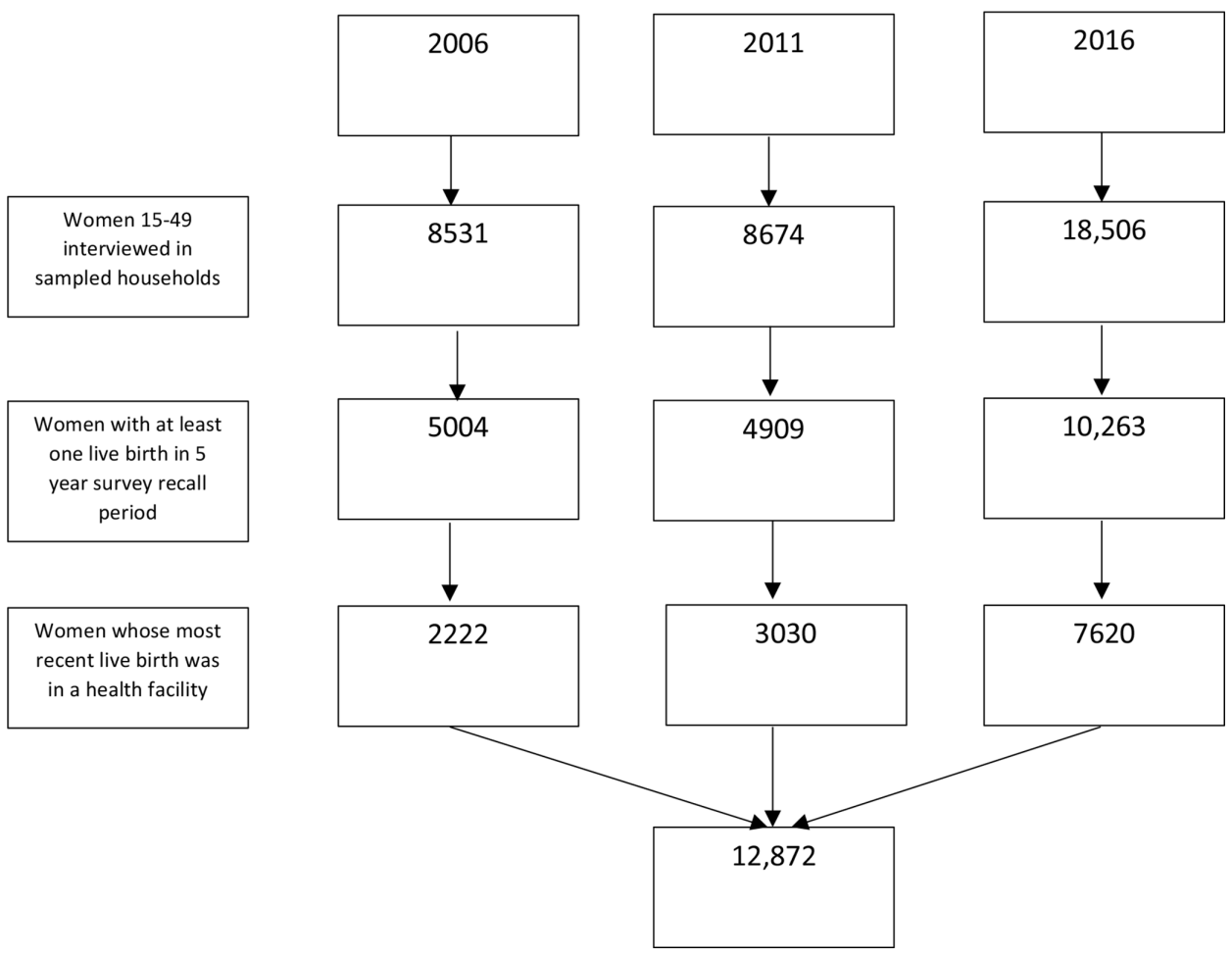

Figure 1 Study population flow diagram.

the elements of stratification and clustering are needed in analysis to adjust for this design and for non-response.

\section{Population}

The most recent live birth within a recall period of 5 years to women aged 15-49 at the time of survey, was included in the analysis, if the birth occurred in a health facility. Data from prior births or from those outside of a facility were excluded (figure 1). This resulted in a total of 12 872 eligible mothers included for analysis.

\section{Definitions}

Our main outcome is the women's report of receiving immediate postnatal health check by a healthcare professional within 24 hours of childbirth while still in the healthcare facility. This was a binary outcome (yes/ no). This variable was created with a conceptual link to the WHO Postnatal care recommendations, which state that all women giving birth in healthcare facilities and their babies should remain in the health facility for a minimum of 24 hours following uncomplicated vaginal childbirth, and receive frequent routine postnatal care checks during this period. ${ }^{15}$

We used four variables to construct this outcome, based on separate questions that women were asked: (1) whether the woman received a postnatal check while still in the facility; (2) length of stay of woman in the facility where the birth took place; (3) timing of the first postnatal check in the facility where birth took place and (4) cadre of professional conducting the first postnatal check on mother. As per the WHO recommendations, we would expect optimal immediate postnatal care to be $100 \%$ coverage.
There were no differences in the question wording used in the three surveys. Women who reported a stay in the facility of under 24 hours after childbirth needed to have received such a check before discharge. Among women who remained at the facility for 24 hours or more, we used the timing of the postnatal check variable to determine whether the first postnatal health check occurred within 24 hours of childbirth. We categorised health professionals as: doctor, nurse/midwife and medical assistant/clinical officer. To analyse the timing of the postnatal checks within 24 hours among those who received one, we used the women's response to the question on timing of the first postnatal check in the facility where birth took place and constructed the following categories: (1)<1 hours; (2) 1-4 hours; (3) 4-8 hours; (4) 8-12 hours and (5) 12-24 hours.

We were additionally interested in the women's report of whether babies delivered in health facilities received a postnatal health check by a health care professional within 24 hours of childbirth while still in the healthcare facility or not. This was done to examine missed opportunity where one of the dyad is checked but not the other. To construct this outcome, we used a composite of four variables akin to the process of constructing the maternal receipt of postnatal care outcome.

\section{Conceptual framework}

We reviewed existing published literature to form a list of key variables noted to impact coverage of postnatal care to create our conceptual framework (figure 2). These were grouped into four categories (socio-demographic factors, access to healthcare, perceived need, and 


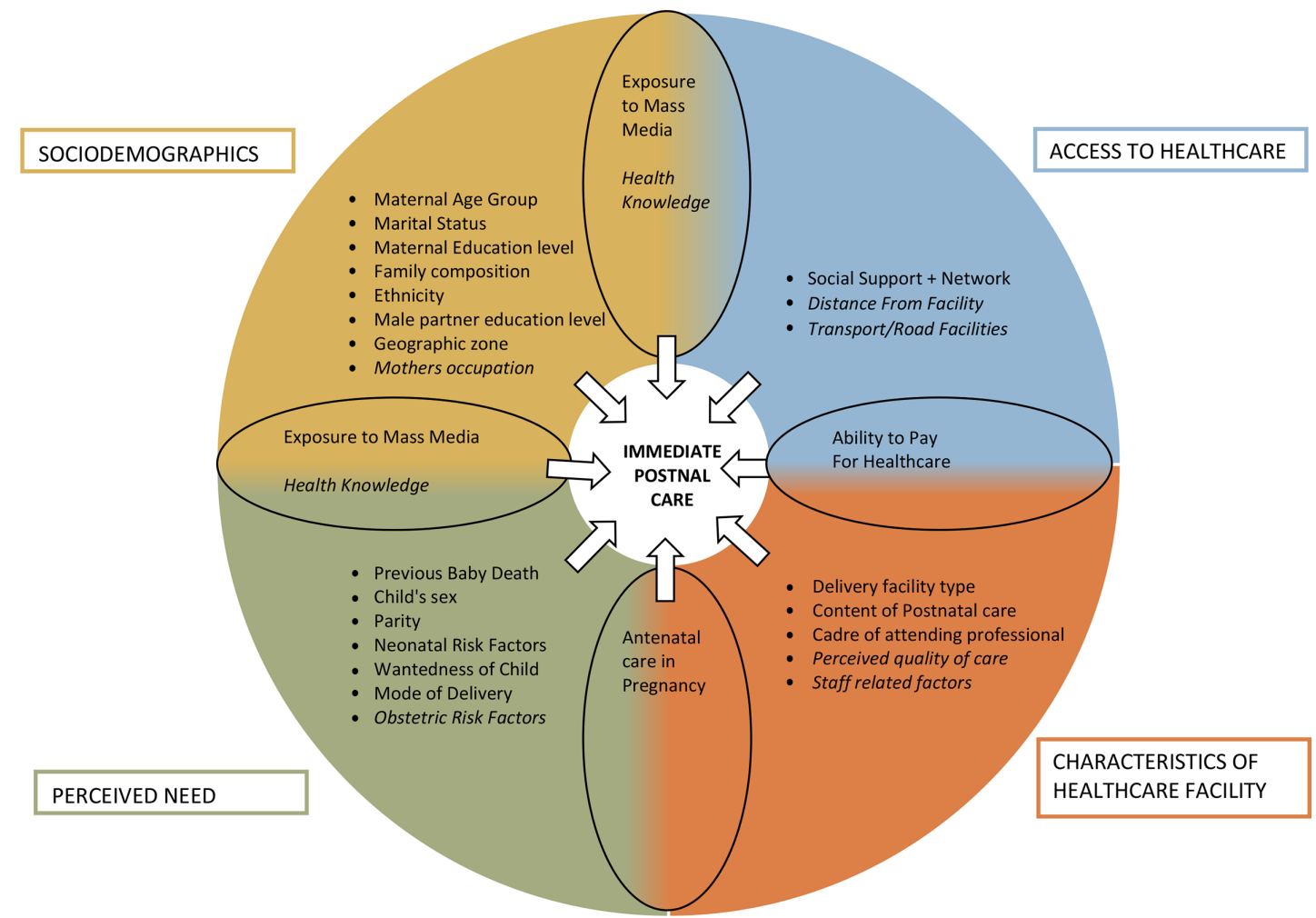

Figure 2 Conceptual framework displaying key factors thought to influence coverage of immediate postnatal care.

characteristics of healthcare facility). Some factors fell into multiple conceptual categories which have been highlighted in the shaded intersecting portions of the diagram. Unfortunately for certain factors, there were no matching questions asked in the DHS questionnaire and therefore these factors remained in our framework but were not examined in analysis (these are in italics).

\section{Perceived need}

Seven dimensions of perceived need for postnatal care were identified, including wantedness of child (wanted at the time of pregnancy or not), mode of delivery (vaginal or caesarean), and child sex (female, male). Parity was categorised as first birth, 2-3, 4-5 and 6+births. We were not able to include obstetric or neonatal risk factors (eg, maternal comorbidities and fetal abnormalities) because the DHS did not collect data pertaining to these dimensions. For obstetric risk factors, we considered using proxies such as maternal body mass index and anaemia, however, these data related to the woman at time of the survey and not at time of birth. We, therefore, chose not to include these proxies. For neonatal risk factors, we used the proxy perceived size of the baby at birth which was categorised as very small or not. This was reflective of the perceived need for care by mother as babies perceived to be smaller by the mother are more likely to be seen to and checked. For the dimension 'death of a previous baby', we constructed a new variable for previous baby death (no child death, child death within 24 hours of birth, child death later than 24 hours of birth). This variable was explored through sensitivity subgroup analysis of women with previous children (parity $>1$ ).

Antenatal care (ANC) in pregnancy was thought to reflect both perceived need and characteristics of healthcare facility. As those women who received facility based ANC were likely to give birth in that same facility. This dimension was examined by categorising the number of ANC visits during the pregnancy (no ANC, 1-3 visits, 4+visits).

Health knowledge and exposure to mass media were thought to reflect the perceived need and sociodemographic factors. There were no questions in the DHS that assessed health knowledge and this dimension could therefore not be analysed further. Exposure to mass media was explored through the variables; any use of television, internet, newspaper and radio (or not) at the time of the survey.

\section{Sociodemographic factors}

We considered eight sociodemographic factors for inclusion into the model. Maternal age group at birth of baby (in 5-year age groups), marital status (married or cohabiting at time of survey or not), highest maternal education level (no education, primary education, secondary and higher education) and ethnicity (Christian, other religions) were assessed. The boundaries of districts and regions changed over the ten-year period covered by the three DHS and were not identical. We, therefore, constructed four larger zones (Eastern, Western, Northern, Central-see online supplemental material 1) which are consistent over time, as done previously. ${ }^{6}$ 
Family composition was assessed by number of persons $(<4,4-5,6+$ persons $)$ and number of children under the age of 5 years $(0-1,2-3,4+)$ in the woman's household. Women's occupation was not examined, as data in DHS pertained to the time of the survey and not at the time of index birth. Household wealth quintile, place of residence (urban vs rural) and the woman's autonomy were thought to reflect both socio-demographic factors and access to healthcare factors. Household wealth quintiles were provided in the dataset and constructed using principal component analysis of household assets using an established method. ${ }^{6}$ The dimension of financial autonomy was explored with the binary variable of the woman having a bank account or not. Further exploration of autonomy to healthcare and finances was conducted in sensitivity analysis among married women through the variables who makes decisions about healthcare and finances (respondent alone, respondent and male partner, male partner alone, other). Male partner's highest education level (no education, primary education, secondary/higher education) was explored further in subgroup analysis among women married at the time of survey.

\section{Characteristics of healthcare facility}

We identified five dimensions related to characteristics of the healthcare facility where the birth occurred. We categorised the sector of the facility as public (government hospital, government health centre, other public sector) or private (private hospital/clinic, other private medical sector). Assistance with the birth was captured by considering the highest cadre listed (doctor/non-physician clinicians, nurse/midwife, other/none). Staff-related factors were conceptually important, but not available on DHS. The dimension patient perceived quality of care was not directly asked within the DHS and no proxies for this dimension could be found. There were no direct variables that asked women to recall the content of their postnatal care. We used the variable of whether the woman reported that the baby was weighed (or not) as a proxy for this dimension as it is reflective of the available staffing, procedures and resources.

\section{Access to healthcare}

We were able to assess one dimension-social support and network-for access to healthcare. This dimension was captured by the two created variables: number of persons $(<4,4-5,6+$ persons $)$ and number of children under the age of 5 in the woman's household $(0-1,2-3$, $4+)$. The distance of the house to the nearest facility or the facility where the birth occurred, or transport/road facilities are not captured on the DHS. Ability to pay for healthcare was thought to reflect both characteristics of healthcare facility and access to healthcare. The variable of whether the woman was covered by health insurance or not was used to reflect this dimension.

\section{Statistical analysis}

All analyses were conducted in STATA V.16 SE. Analysis included descriptive statistics of demographic characteristics of women who gave birth in health facilities on all three surveys. Among women who gave birth in health facilities, we computed the percentage who reported receiving immediate maternal postnatal care. Among women with such a check, we described the distribution of the timing of the first check. We calculated the percentage of babies born in health facilities receiving a postnatal check within 24 hours, disaggregated by type of facility.

For the 2016 survey, we conducted an analysis of mother-baby dyads and calculated the percentage receiving immediate postnatal care within 24 hours while still in healthcare facilities for mother only, baby only, both and neither. Additionally, we used logistic regression to explore the crude associations between factors outlined in the conceptual framework and the woman's receipt of immediate postnatal care by a health professional in the facility. A multivariable logistic regression model was created by analysing each individual variable and excluding those that were collinear with existing variables. This enabled the multivariable model to be a reflection of the conceptual model.

Two sensitivity analyses using crude and multivariable logistic regression were conducted. First, among the subsample of women married/cohabiting at the time of survey, we additionally included highest level of male partner education, and autonomy with finances and healthcare. Among women with previous children, the model included previous baby death.

We used the survey set command to adjust all analyses for survey sampling design and non-response using individual sampling weights, stratification and clustering.

\section{Missing data}

There were low levels of missing data in the variables used. We describe how missing values were handled in online supplemental material 2.

It was not appropriate or possible to involve patients or the public in the design, or conduct, or reporting, or dissemination plans of our research.

\section{RESULTS \\ Description of women delivering in healthcare facilities 2006-2016}

The sample of women who gave birth in health facilities was 2222 (2006), 3030 (2011) and 7620 (2016). The percentage of most recent births in healthcare facilities increased from $44.6 \%$ (95\% CI: $41.9 \%$ to $47.3 \%$ ) in 2006 to $60.1 \%$ (95\% CI: $57.2 \%$ to $62.9 \%$ ) in 2011 to $75.2 \%$ (95\% CI: $73.4 \%$ to $77.0 \%$ ) in 2016 .

Sociodemographic characteristics of women who gave birth in health facilities on each survey are shown in table 1 . The majority of births in healthcare facilities were in the public sector on all three surveys.

\section{Receipt of immediate maternal postnatal care}

Table 2 reflects the receipt of immediate maternal postnatal care in women who had a health facility birth. 


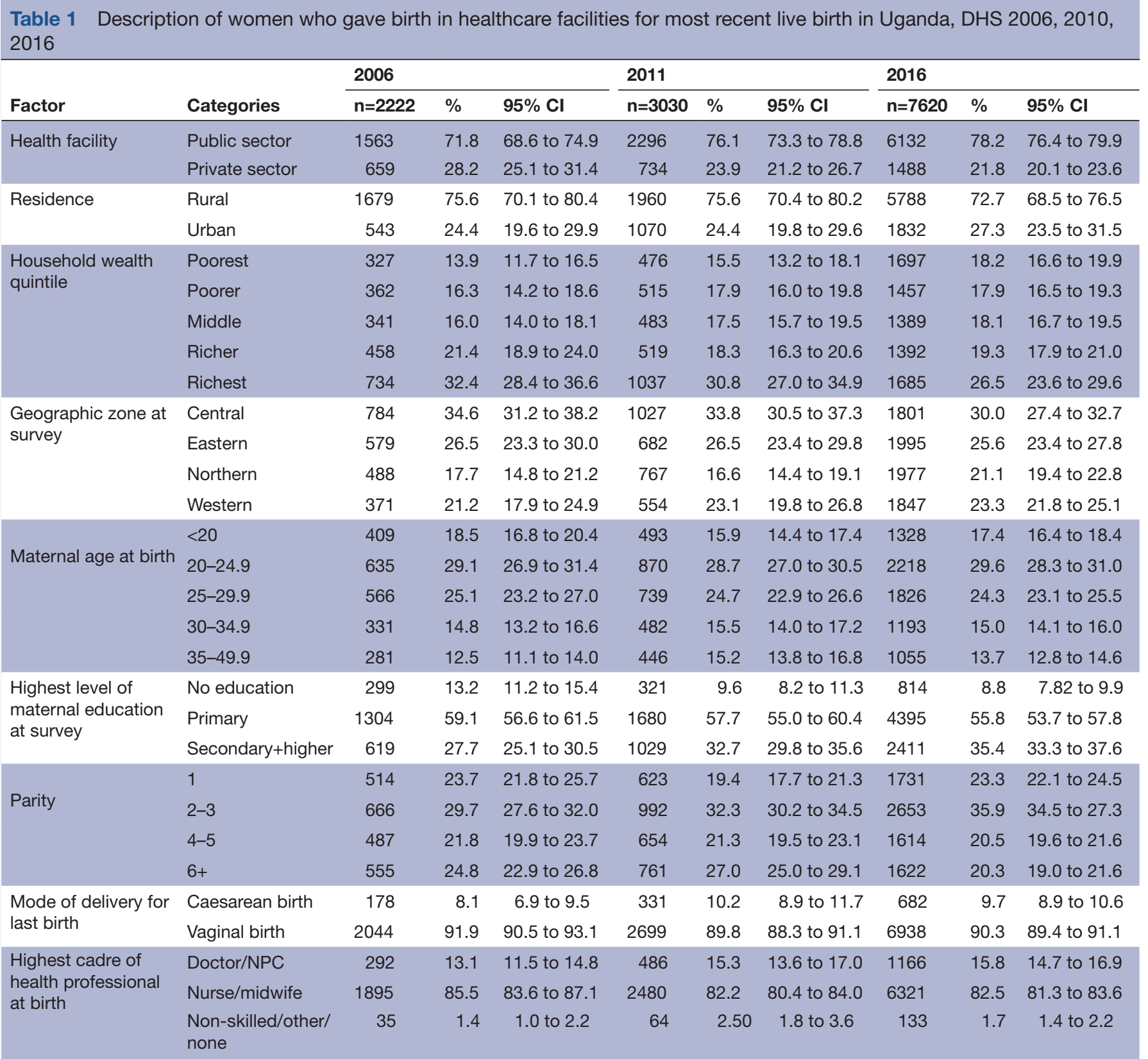

NPC, non-physician clinician (includes medical assistant, clinical officer).

Among women who gave birth in healthcare facilities, the percentage that reported receiving an immediate postnatal check increased from $35.7 \%$ (95\% CI $33.4 \%$ to $38.1 \%$ ) in 2006 to $46.6 \%$ in 2011 to $65.0 \%$ (95\% CI: $63.2 \%$ to $66.7 \%$ ) in 2016 . These increases occurred across all social and demographic groups of women. However, in 2016, wide variations in receiving immediate maternal postnatal care remained, particularly in the Western zone, which was far lower than the other zones, and lower among women who had a vaginal birth compared with those with a caesarean section.

In 2016, $67.6 \%$ (95\% CI: $65.8 \%$ to $69.3 \%$ ) of babies born in healthcare facilities received immediate postnatal care. Among the 7620 mother-baby dyads, in $57.9 \%$ both the woman and the baby received immediate postnatal care, in $25.4 \%$ neither the mother nor the baby received immediate postnatal care, in $7.1 \%$ only the mother and in $9.6 \%$ only the baby received immediate postnatal care.

\section{Timing of first maternal postnatal check in healthcare facilities on 2006, 2011, 2016 surveys}

Table 3 presents the timing of first maternal postnatal check in healthcare facilities. Across the three surveys, among women who received a postnatal check within 24 hours, the most common time period for the first postnatal check was 1-4 hours after birth; this level was similar in facilities from both sectors. The overall mean time for the first postnatal check decreased from 7.3 hours after birth in 2006 to 4.5 hours in 2011 to 3.1 hours in 2016; and the median time from 4 hours to 2 hours to 1 hour. 
Table 2 Percentage of women delivering in healthcare facilities who reported receiving immediate postnatal care in Uganda DHS 2006, 2011, 2016

\begin{tabular}{|c|c|c|c|c|c|c|c|c|c|c|}
\hline \multirow[b]{2}{*}{ Factor } & \multirow[b]{2}{*}{ Categories } & \multicolumn{3}{|l|}{2006} & \multicolumn{3}{|l|}{2011} & \multicolumn{3}{|l|}{2016} \\
\hline & & $\mathbf{n}$ & $\%$ & $95 \% \mathrm{Cl}$ & $\mathrm{n}$ & $\%$ & $95 \% \mathrm{Cl}$ & $\mathbf{n}$ & $\%$ & $95 \% \mathrm{Cl}$ \\
\hline Overall & & 805 & 35.7 & 33.4 to 38.1 & 1456 & 46.6 & 44.0 to 49.3 & 4997 & 65.0 & 63.2 to 66.7 \\
\hline \multirow[t]{2}{*}{ Health facility } & Public sector & 555 & 35.3 & 32.7 to 38.0 & 1110 & 47.0 & 44.1 to 49.9 & 4005 & 64.4 & 62.6 to 66.2 \\
\hline & Private sector & 250 & 36.6 & 32.2 to 41.3 & 734 & 45.5 & 40.2 to 50.9 & 992 & 66.9 & 63.4 to 70.2 \\
\hline \multirow[t]{2}{*}{ Residence } & Rural & 574 & 33.9 & 31.3 to 36.6 & 8731 & 44.0 & 40.9 to 47.1 & 3720 & 63.0 & 60.9 to 65.1 \\
\hline & Urban & 231 & 41.2 & 35.7 to 46.9 & 585 & 54.7 & 48.9 to 60.4 & 1277 & 70.2 & 66.9 to 73.3 \\
\hline \multirow{5}{*}{$\begin{array}{l}\text { Household wealth } \\
\text { quintile }\end{array}$} & Poorest & 111 & 32.9 & 26.3 to 40.2 & 234 & 47.5 & 41.7 to 53.3 & 1151 & 65.7 & 61.6 to 69.6 \\
\hline & Poorer & 104 & 28.8 & 23.5 to 34.8 & 203 & 39.3 & 34.2 to 44.6 & 926 & 61.6 & 58.1 to 64.9 \\
\hline & Middle & 103 & 29.9 & 24.7 to 35.8 & 199 & 38.3 & 33.2 to 43.7 & 842 & 59.8 & 56.4 to 63.0 \\
\hline & Richer & 155 & 32.7 & 28.3 to 37.4 & 238 & 45.5 & 40.7 to 50.4 & 854 & 61.7 & 58.2 to 65.1 \\
\hline & Richest & 332 & 45.2 & 41.1 to 49.4 & 582 & 55.9 & 51.1 to 60.1 & 1224 & 72.7 & 65.0 to 75.6 \\
\hline \multirow{4}{*}{$\begin{array}{l}\text { Geographic zone at } \\
\text { survey }\end{array}$} & Central & 329 & 42.1 & 38.4 to 45.9 & 581 & 56.4 & 52.1 to 60.6 & 1268 & 69.9 & 66.5 to 73.1 \\
\hline & Eastern & 222 & 40.1 & 35.7 to 44.8 & 306 & 46.7 & 42.0 to 51.4 & 1413 & 69.0 & 65.1 to 72.6 \\
\hline & Northern & 168 & 31.1 & 25.2 to 37.6 & 374 & 46.3 & 41.6 to 51.1 & 1378 & 68.6 & 64.6 to 72.4 \\
\hline & Western & 86 & 23.5 & 19.4 to 28.1 & 195 & 32.5 & 27.5 to 37.9 & 938 & 50.9 & 47.9 to 53.9 \\
\hline \multirow[t]{5}{*}{ Maternal age at birth } & $<20$ & 133 & 34.3 & 29.4 to 39.5 & 238 & 45.7 & 40.8 to 50.7 & 822 & 61.0 & 57.9 to 64.1 \\
\hline & $20-24.9$ & 221 & 32.8 & 29.0 to 36.9 & 425 & 46.8 & 42.4 to 51.3 & 1440 & 64.9 & 62.0 to 67.7 \\
\hline & $25-29.9$ & 203 & 35.1 & 30.9 to 39.5 & 341 & 45.2 & 40.5 to 49.9 & 1224 & 65.7 & 62.9 to 68.4 \\
\hline & $30-34.9$ & 136 & 40.3 & 34.9 to 45.9 & 232 & 47.6 & 42.6 to 52.7 & 815 & 67.5 & 63.9 to 70.9 \\
\hline & $35-49.9$ & 112 & 40.1 & 34.0 to 38.1 & 220 & 48.7 & 43.1 to 54.3 & 696 & 65.9 & 62.4 to 69.3 \\
\hline \multirow{3}{*}{$\begin{array}{l}\text { Highest level of } \\
\text { maternal education at } \\
\text { survey }\end{array}$} & No education & 92 & 30.3 & 25.0 to 36.3 & 152 & 41.5 & 35.4 to 47.9 & 558 & 64.1 & 59.4 to 68.6 \\
\hline & Primary & 415 & 31.5 & 28.8 to 34.4 & 728 & 42.6 & 39.7 to 45.6 & 2726 & 61.3 & 59.2 to 63.3 \\
\hline & Secondary+higher & 298 & 47.0 & 42.6 to 51.5 & 576 & 55.3 & 50.4 to 60.0 & 1713 & 71.0 & 68.6 to 73.3 \\
\hline \multirow[t]{4}{*}{ Parity } & 1 & 185 & 36.7 & 32.2 to 41.4 & 311 & 45.7 & 40.6 to 51.0 & 1162 & 66.9 & 63.9 to 69.7 \\
\hline & $2-3$ & 262 & 38.0 & 33.7 to 42.5 & 522 & 52.3 & 47.9 to 56.7 & 1722 & 64.4 & 62.0 to 66.8 \\
\hline & $4-5$ & 158 & 31.5 & 27.3 to 36.0 & 288 & 42.8 & 38.5 to 47.2 & 1072 & 65.6 & 62.5 to 68.6 \\
\hline & $6+$ & 200 & 35.7 & 31.2 to 40.4 & 335 & 43.5 & 39.6 to 47.4 & 1041 & 63.1 & 60.0 to 66.2 \\
\hline \multirow{2}{*}{$\begin{array}{l}\text { Mode of delivery for } \\
\text { last birth }\end{array}$} & Caesarean birth & 101 & 55.6 & 46.6 to 64.3 & 199 & 61.6 & 54.8 to 68.1 & 565 & 82.2 & 78.4 to 85.4 \\
\hline & Vaginal birth & 704 & 33.9 & 31.5 to 36.4 & 1257 & 44.9 & 42.2 to 47.7 & 4432 & 63.1 & 61.3 to 64.9 \\
\hline \multirow{3}{*}{$\begin{array}{l}\text { Highest cadre of } \\
\text { health professional } \\
\text { at birth }\end{array}$} & Doctor/NPC & 136 & 45.3 & 38.5 to 52.2 & 283 & 59.8 & 54.4 to 65.0 & 853 & 73.3 & 69.8 to 76.4 \\
\hline & Nurse/midwife & 661 & 34.4 & 32.0 to 37.0 & 1154 & 44.9 & 42.1 to 47.8 & 4072 & 63.6 & 61.8 to 65.4 \\
\hline & $\begin{array}{l}\text { Non- skilled/other/ } \\
\text { none }\end{array}$ & 8 & 22.8 & 10.1 to 43.7 & 19 & 22.7 & 13.4 to 35.8 & 72 & 52.9 & 42.9 to 62.8 \\
\hline
\end{tabular}

NPC, non-physician clinician.

\section{Factors associated with immediate maternal postnatal check on the 2016 survey}

Table 4 presents the association of key factors with receiving an immediate maternal postnatal check in the most recent survey.

In the multivariable analysis, compared with receiving no facility-based ANC, those with 1-3 visits had an OR of 2.18 (95\% CI: 1.39 to 4.2 ) and those with $4+$ visits had an OR 2.34 (95\% CI: 1.50 to 3.64) of receiving immediate maternal postnatal care. The use of internet had an OR of 1.39 (95\% CI: 1.04 to 1.86 ) of receiving immediate postnatal care compared with not using the internet. Having the baby weighed at birth had an OR of 1.84 (95\% CI: 1.58 to 2.14 ) of receiving immediate postnatal care compared with not being weighed at birth. Mode of delivery was also an important factor; women who had a caesarean section were 2.93 times (95\% CI: 2.28 to 3.75$)$ more likely to receive immediate postnatal care compared with those who had a vaginal birth in a health facility.

\section{Additional analyses}

Within a subsample of 6211 women who were married or cohabiting at the time of the survey (online supplemental material 3), we found in multivariable analysis that male partner's education was not significantly associated with receipt of immediate postnatal care among women. We analysed a separate sub-sample of 5889 women who had 
Table 3 Distribution, mean and median time of first postnatal check in women having immediate postnatal care in healthcare facilities by sector in Uganda DHS 2006, 2011, 2016

\begin{tabular}{|c|c|c|c|c|c|}
\hline & Categories & $\mathbf{n}$ & Overall & Public sector & Private sector \\
\hline \multirow[t]{7}{*}{2006} & $<1$ hour & 90 & $11.0 \%$ & $10.8 \%$ & $11.5 \%$ \\
\hline & $1-4$ hours & 352 & $44.1 \%$ & $42.9 \%$ & $46.6 \%$ \\
\hline & 5-8 hours & 150 & $18.6 \%$ & $19.0 \%$ & $17.7 \%$ \\
\hline & 9-12 hours & 59 & $7.2 \%$ & $7.8 \%$ & $5.9 \%$ \\
\hline & 13-24 hours & 154 & $19.1 \%$ & $19.5 \%$ & $18.3 \%$ \\
\hline & Distribution in hours & & Mean (median) & Mean (median) & Mean (median) \\
\hline & Total & 805 & $7.25(4)$ & $7.36(4)$ & $6.99(3)$ \\
\hline \multirow[t]{7}{*}{2011} & $<1$ hour & 261 & $18.9 \%$ & $16.4 \%$ & $27.1 \%$ \\
\hline & $1-4$ hours & 756 & $52.6 \%$ & $53.7 \%$ & $49.1 \%$ \\
\hline & 5-8 hours & 213 & $14.3 \%$ & $15.1 \%$ & $11.8 \%$ \\
\hline & $9-12$ hours & 89 & $6.0 \%$ & $6.8 \%$ & $3.4 \%$ \\
\hline & 13-24 hours & 137 & $8.2 \%$ & $8.0 \%$ & $8.6 \%$ \\
\hline & Distribution in hours & & Mean (median) & Mean (median) & Mean (median) \\
\hline & Total & 1456 & $4.49(2)$ & $4.61(2)$ & $4.11(2)$ \\
\hline \multirow[t]{7}{*}{2016} & $<1$ hour & 1565 & $31.8 \%$ & $30.0 \%$ & $38.4 \%$ \\
\hline & $1-4$ hours & 2520 & $49.5 \%$ & $50.1 \%$ & $47.5 \%$ \\
\hline & $5-8$ hours & 513 & $10.3 \%$ & $11.1 \%$ & $7.4 \%$ \\
\hline & $9-12$ hours & 190 & $3.7 \%$ & $3.8 \%$ & $3.1 \%$ \\
\hline & 13-24 hours & 209 & $4.7 \%$ & $5.0 \%$ & $3.6 \%$ \\
\hline & Distribution in hours & & Mean (median) & Mean (median) & Mean (median) \\
\hline & Total & 4997 & $3.09(1)$ & $3.23(1)$ & $2.62(1)$ \\
\hline
\end{tabular}

a previous child (online supplemental material 3). In multivariable analysis, women who reported a previous child dying within 24 hours of birth were not more likely to have reported an immediate maternal postnatal check than women without a previous child death (adjusted OR 1.05 (95\% CI: 0.80 to 1.38$)$ )

\section{DISCUSSION}

Over the 15-year period under investigation, when the percentage of births in health facilities increased, the percentage of women who remained in health facilities for 24 hours or longer remained stable at just above $70 \%$, and coverage of immediate maternal postnatal care after facility birth increased to $65.0 \%$. We found large geographic variations in immediate maternal postnatal care after facility births on the 2016 survey, particularly between Western and Eastern Uganda. In the 2016 survey, the proportion of babies and mothers receiving immediate postnatal care was similar. The majority of first postnatal checks after facility births occurred at 1-4 hours post partum and the median time interval from birth to first check reduced between 2006 and 2016 surveys, with the shift towards earlier checks most marked in private sector facilities. The most significant factor independently associated with receipt of immediate postnatal care was mode of delivery; women who had a caesarean section had nearly three times the odds of immediate postnatal care compared with those with a vaginal birth. Other factors positively associated with higher odds of being checked included exposure to mass media, baby having been weighed at birth, and receipt of ANC.

Our findings show the most significant improvement to postnatal care provision occurred between 2011 and 2016 where coverage increased by $20 \%$. This is in line with the $15.1 \%$ increase in deliveries in healthcare facilities in line with current global trends and recommendations. Despite this, immediate postnatal care coverage after such births remained suboptimal at $65 \% .^{1527}$ This rate is higher than the $50 \%$ coverage reported in Uganda by Ndugga et al, although this report included births at both home and facility. ${ }^{28} \mathrm{~A}$ common reason given for poor coverage of care is that women do not remain in facilities long enough (for 24 hours) to receive postnatal care. ${ }^{16}$ However, our study shows that even if women do stay for 24 hours, the coverage of immediate postpartum checks still remains suboptimal. As such, this finding may be more reflective of the lack of priority given to mothers in the postpartum period..$^{29}$ At present, coverage of immediate postpartum checks is globally poor and the worst performing aspect in the obstetric continuum of care. ${ }^{78}$ In fact, there is no current global standard metric available to evaluate progress in quality and content of care which otherwise exists for both antenatal and intrapartum care. ${ }^{30}$ Additionally, with the increased number 
Table 4 Bivariate and multivariable logistic analysis of factors of coverage of immediate maternal postnatal care of woman who gave birth in healthcare facilities for most recent live births in Uganda 2016

\section{Crude analysis}

$(n=7620)$

Multivariable analysis $(n=7620)$

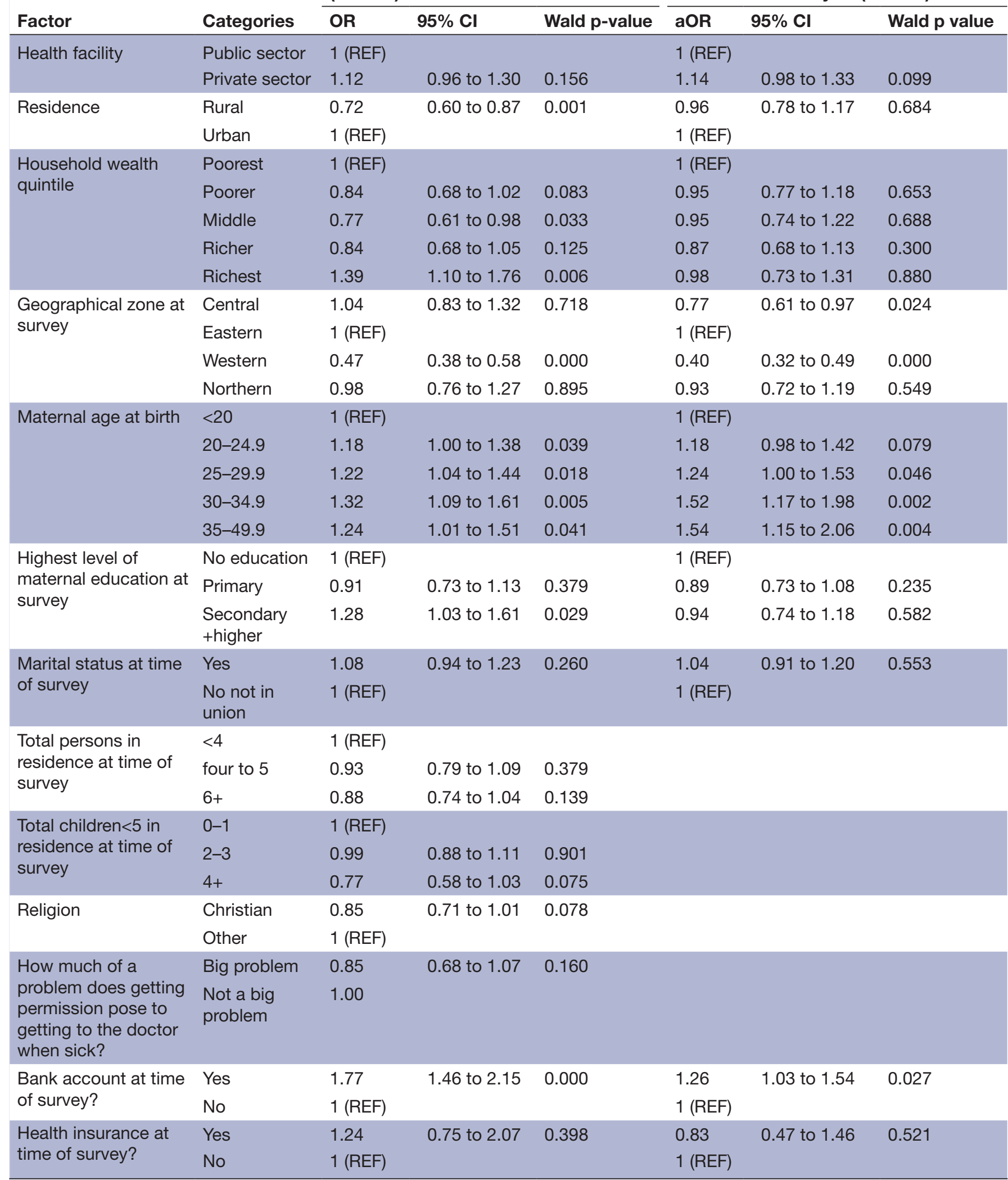

Continued 
Table 4 Continued

\begin{tabular}{|c|c|c|c|c|c|c|c|}
\hline \multirow[b]{2}{*}{ Factor } & \multirow[b]{2}{*}{ Categories } & \multicolumn{3}{|c|}{$\begin{array}{l}\text { Crude analysis } \\
(\mathrm{n}=7620)\end{array}$} & \multicolumn{3}{|c|}{ Multivariable analysis $(n=7620)$} \\
\hline & & OR & $95 \% \mathrm{Cl}$ & Wald p-value & aOR & $95 \% \mathrm{Cl}$ & Wald $p$ value \\
\hline \multirow{3}{*}{$\begin{array}{l}\text { No of ANC } \\
\text { attendances at } \\
\text { healthcare facilities }\end{array}$} & None & 1 (REF) & & & 1 (REF) & & \\
\hline & $1-3$ visits & 2.43 & 1.55 to 3.83 & 0.000 & 2.18 & 1.39 to 3.42 & 0.001 \\
\hline & $4+$ visits & 2.74 & 1.74 to 4.31 & 0.000 & 2.34 & 1.50 to 3.64 & 0.000 \\
\hline \multirow{2}{*}{$\begin{array}{l}\text { Read a newspaper at } \\
\text { time of survey }\end{array}$} & Yes & 1.89 & 1.60 to 2.22 & 0.000 & 1.38 & 1.15 to 1.65 & 0.000 \\
\hline & Not at all & 1 (REF) & & & 1 (REF) & & \\
\hline \multirow{2}{*}{$\begin{array}{l}\text { Listened to the radio } \\
\text { at time of survey }\end{array}$} & Yes & 1.22 & 1.08 to 1.43 & 0.002 & 1.13 & 0.98 to 1.31 & 0.091 \\
\hline & Not at all & 1 (REF) & & & 1 (REF) & & \\
\hline \multirow{2}{*}{$\begin{array}{l}\text { Watched TV at time of } \\
\text { survey }\end{array}$} & Yes & 1.49 & 1.28 to 1.72 & 0.000 & & & \\
\hline & Not at all & 1 (REF) & & & & & \\
\hline \multirow{2}{*}{$\begin{array}{l}\text { Use of internet at time } \\
\text { of survey }\end{array}$} & Yes & 2.40 & 1.88 to 3.08 & 0.000 & 1.39 & 1.04 to 1.86 & 0.027 \\
\hline & Not at all & 1 (REF) & & & 1 (REF) & & \\
\hline \multirow{2}{*}{$\begin{array}{l}\text { Mobile phone at time } \\
\text { of survey }\end{array}$} & Yes & 1.24 & 1.10 to 1.41 & 0.000 & 0.96 & 0.84 to 1.09 & 0.501 \\
\hline & No & 1 (REF) & & & 1 (REF) & & \\
\hline \multirow[t]{4}{*}{ Parity } & One & 1 (REF) & & & 1 (REF) & & \\
\hline & Two-three & 0.89 & 0.77 to 1.04 & 0.140 & 0.83 & 0.70 to 0.99 & 0.033 \\
\hline & Four-five & 0.95 & 0.79 to 1.13 & 0.547 & 0.83 & 0.66 to 1.04 & 0.110 \\
\hline & Six+ & 0.85 & 0.71 to 1.01 & 0.068 & 0.75 & 0.57 to 0.98 & 0.036 \\
\hline \multirow{2}{*}{$\begin{array}{l}\text { Wantedness of last } \\
\text { pregnancy at time of } \\
\text { pregnancy }\end{array}$} & Wanted & 1 (REF) & & & 1 (REF) & & \\
\hline & Unwanted & 0.85 & 0.76 to 0.95 & 0.003 & 0.87 & 0.78 to 0.98 & 0.019 \\
\hline \multirow[t]{2}{*}{ Sex of last baby } & Female & 1.06 & 0.95 to 1.20 & 0.255 & 1.10 & 0.98 to 1.24 & 0.116 \\
\hline & Male & 1 (REF) & & & 1 (REF) & & \\
\hline \multirow{2}{*}{$\begin{array}{l}\text { Was baby weighed at } \\
\text { birth }\end{array}$} & Yes & 2.08 & 1.79 to 2.42 & 0.000 & 1.84 & 1.58 to 2.14 & 0.000 \\
\hline & No & 1 (REF) & & & 1 (REF) & & \\
\hline \multirow{2}{*}{$\begin{array}{l}\text { How big did the } \\
\text { woman think the baby } \\
\text { was at birth }\end{array}$} & Other & 1 (REF) & & & & & \\
\hline & Very small & 0.87 & 0.68 to 1.11 & 0.259 & & & \\
\hline \multirow{3}{*}{$\begin{array}{l}\text { Start time of breast } \\
\text { feeding }\end{array}$} & Within an hour & 1 (REF) & & & 1 (REF) & & \\
\hline & $>1$ hours & 0.95 & 0.83 to 1.09 & 0.474 & 0.72 & 0.62 to 0.83 & 0.000 \\
\hline & Yes-CS & 2.70 & 2.13 to 3.41 & 0.000 & 2.93 & 2.28 to 3.75 & 0.000 \\
\hline $\begin{array}{l}\text { Mode of delivery for } \\
\text { last birth }\end{array}$ & No-vaginal & 1 (REF) & & & 1 (REF) & & \\
\hline \multirow{3}{*}{$\begin{array}{l}\text { Highest cadre of } \\
\text { health professional at } \\
\text { birth }\end{array}$} & Doctor/NPC & 1.56 & 1.32 to 1.84 & 0.000 & & & \\
\hline & Nurse/midwife & 1 (REF) & & & & & \\
\hline & Other/none & 0.64 & 0.43 to 0.96 & 0.03 & & & \\
\hline
\end{tabular}

ANC, antenatal care; aOR, adjusted OR; CS, Caesarean section; NPC, non-physician clinician; TV, television.

of facility births, health facilities are busier than ever before. The poor coverage of immediate care could therefore be a sign of overburdened and burned-out healthcare providers struggling to keep up with the increasing demand. ${ }^{31}$ Furthermore, although WHO Postnatal care recommendations do exist, there is a paucity of literature providing guidance and frameworks to health workers at country or system level on how to provide high quality maternal care, particularly after facility birth. ${ }^{32}$ As a result, the care provided is often incomplete and not universal to every women at birth. ${ }^{17}$

Although not universal, women from Eastern Uganda were noted to receive the highest coverage of immediate postnatal care after facility birth. In a cross-sectional study of factors affecting utilisation of early postnatal care (within 7 days of birth) in Eastern Uganda following health facility births, formal employment was identified as the key socioeconomic factor increasing the likelihood of 
women receiving early postnatal care. ${ }^{33}$ Through employment, women not only have a better financial status and ability to use quality health services but are also empowered to participate in the decision-making process about their healthcare. ${ }^{33}$ DHS data do not provide the means to accurately examine the role of a women's occupation on receipt of immediate postnatal care and therefore it might be useful to examine this factor directly at regional level. Interestingly, there was poorer coverage of care in Central Uganda than Eastern Uganda. The Central Uganda region contains Kampala, the capital and largest city in Uganda. Coupled with the rise in health facility births, crowding does exist within facilities and this has been found to have an ongoing detrimental effect on the quality of respectful care received by women. ${ }^{81}$ Other examples of a lack of respectful postnatal care in Uganda (physical and verbal mistreatment by staff, and stigma and denial of care for marginalised communities) have been shown to contribute to a negative care experience by mothers. ${ }^{34}$ This has resulted in a reduced utilisation and therefore coverage of postnatal care services. ${ }^{35}$ Again, data for respectful care were not collected in the DHS and this would also be worth examining directly at regional level.

Conceptually, a key factor thought to impact maternal immediate postnatal care provision is if immediate postnatal care is provided for the baby. In the 2016 survey, nearly two-thirds of mother-baby dyads received both maternal and neonatal immediate postnatal care, while a quarter did not receive any immediate postnatal care for either mother or baby. Very few women reported receiving only maternal or only neonatal immediate postnatal care. This suggests that if a baby is to receive immediate postnatal care, a mother is likely to as well, and vice versa. This finding is perhaps driven by the notion that those mothers and babies with complications (eg, mothers most unwell following birth or with existing conditions, and babies which are smaller, premature or who are most unwell), will be prioritised to receive care. ${ }^{34}$ This idea is further exemplified in our multivariable model which found reporting that the baby was weighed at birth was positively associated with the mother received an immediate postnatal check. To our knowledge, there is no existing literature examining this interaction. With this knowledge, further work perhaps should focus on integrating maternal and newborn immediate postnatal care within in-facility postnatal care guidelines to aid in improving coverage of overall immediate postnatal care. ${ }^{8}$

The timing of the first postnatal check, examined in all datasets, found that the majority of first checks occurred consistently between 1 and 4 hours. This is in line with Ugandan guidelines and several factors encourage this early postnatal review. ${ }^{22}$ For example, many resourcestretched maternity units are in need of early discharge to make space for new deliveries. ${ }^{16}$ Additionally, for women delivering in private facilities, having an early check will often enable women and babies to leave as soon as possible to reduce the cost incurred for time spent in the facility. ${ }^{16} 36$ Unfortunately, the DHS did not gather data on quality or components of postnatal checks, and it was not possible to determine if the speed of check compromises the quality of care provided. Early postnatal checks are not necessarily ideal. ${ }^{16} \mathrm{WHO}$ recommends that all new mothers remain in the facility for 24 hours following birth because the majority of maternal and neonatal deaths occur during this period. ${ }^{9}$ Mothers receiving only one check in the first hour following delivery therefore, without any further checks, might not be sufficiently monitored to detect complications of birth. ${ }^{9} 15$ As such, it has been suggested that in subSaharan Africa $>75 \%$ of women receive suboptimal postnatal health checks. ${ }^{16}{ }^{17}$ Further qualitative work focusing on quality of care and actions taken following postnatal checks would be important to enable this finding to be explored further.

Factors affecting coverage of immediate postnatal care were explored through crude and multivariable logistic regression analysis in the 2016 database. Having a caesarean section increased the odds of being checked compared with those women who had a vaginal delivery which has been noted in existing literature from Bangladesh. ${ }^{37}$ Women having a caesarean section are at a higher risk of severe acute maternal morbidity, particularly in low-resource settings. ${ }^{38}$ As such, clinicians faced with time pressures and a large number of patients to see, might prioritise examining high risk postoperative women. ${ }^{17}$ That said, coverage of immediate postnatal care for mothers giving birth by caesarean section was still suboptimal at $82 \%$ (2016). It is, therefore, imperative that new strategies are looked into to improve postnatal care coverage. In sub-Saharan Africa, up to $20 \%$ of caesarean sections are conducted under general anaesthesia. ${ }^{39}$ Following a long labour and emergency caesarean under general anaesthesia, women can often be drowsy and disorientated resulting in poor recall of birth and postnatal care events. The figure of $82 \%$ coverage should, therefore, be interpreted with caution.

Women who had access to mass media were noted to have a higher likelihood of receiving immediate postnatal care. This finding is in line with previous studies across sub-Saharan Africa. ${ }^{40}$ Mass media can be harnessed as a platform to educate and inform mothers in order increase their access to knowledge and improve their ability to seek care. ${ }^{28}$ In all low-resource settings, education has consistently been noted as key to postnatal care utilisation. ${ }^{41}$ Additionally, coverage of ANC was identified as an important factor. The more antenatal visits a woman received the higher the chance of receiving immediate maternal postnatal care compared with those receiving no ANC in facility. This finding was in line with studies from Ethiopia. ${ }^{42}$ ANC has also been proven a worthy platform to provide effective maternal education to reduce postpartum morbidity and may provide the opportunity for mothers to understand key features of their continuum of care. ${ }^{43}$ This finding could be confounded by wealth/ social capital as well as the presence of any pre-existing 
conditions requiring receipt of more $\mathrm{ANC}$ and therefore resulting in a higher need to be checked postnatally.

\section{Limitations}

By using three DHS datasets from 2006 to 2016, we were able to explore changes over time over 15 years of births based on recall periods and examine the coverage and determinants of coverage of immediate postnatal care in health facilities. There are, however, some limitations to our work. First, the DHS relies on women's recall of the immediate postnatal period up to 5 years preceding the survey. This relies on the accuracy of the woman's memory of the receipt and timing of postnatal care provided in the immediate postnatal period. A study in two sub-Saharan African settings showed that women were able to recall key postnatal events to an acceptable threshold. ${ }^{44}$ However, our results flagged some clear anomalies as across the three surveys women consistently reported caesarean sections being conducted by nurses/ midwives and unskilled birth attendants. This could be that women are actually remembering the latter parts of intrapartum care prior to birth. Studies on the validity of women's recall in the immediate postnatal care have found that women are consistently less able to recall indicators in the intrapartum period and within 1 hour of delivery immediately postnatally. ${ }^{45}$ With checks being conducted earlier, there is additionally a higher chance of women being unable to distinguish between the latter parts of intrapartum care and immediate postnatal care. ${ }^{46}$ We attempted to limit the extent of recall error by restricting responses to the respondents' most recent birth. Second, the DHS questions do not capture the presence of complications, nor the quality and content of postnatal care. Our ability to examine postnatal care comprehensively and adjust for important confounders was therefore somewhat limited. ${ }^{44}$ Third, demographic data within the DHS survey such as marital status are taken at the time of the survey being conducted and not at the time of birth. That said, the DHS recall period of live births is limited to 5 years and thus it limits the extent of discrepancies.

\section{CONCLUSION}

Although there have been significant advances in coverage of postnatal care globally, there still remains a large gap. This article works synergistically with other global papers to strengthen the argument for focus and attention to postnatal care. This is especially relevant and important as it paves the way for new postnatal care guidelines due to be released by WHO in 2021. Future research in postnatal care coverage is key to ensure it gains a pivotal place on the global maternal health agenda. In Uganda, it would be useful to understand the barriers to provision of immediate postnatal care after facility births at national level. This would enable policy stakeholders to galvanise support in prioritising postnatal care provision and equitable coverage. Additionally, it would provide data on how to ensure best practice through guidelines training and implementation. One strategy could be to look at further integrating maternal and newborn care services, even beyond discharge. Another would be to acknowledge that increasing facility-based births or the number of women remaining in facility for 24 hours following birth has not led to the sufficient change needed to make immediate postnatal care coverage universal, nor reduce maternal and neonatal mortality. If anything, the resulting crowding has increased the pressure on overburdened and burned-out healthcare providers, reducing respectful quality postnatal care provision and preventing the swift recognition and action if postnatal complication are identified. Perhaps education and active involvement of mothers and their partners in their care could act to enhance respectful care and improve coverage and utilisation of care. Finally, there is need for a direct needs assessment of health system, staff and quality of care, to identify factors that impede immediate postnatal care coverage. It would be useful for the work to be conducted by region to help uncover the geographical and subnational differences that exist in care provision.

Twitter Teesta Dey @teesta_dey and Lenka Benova @lenkabenova

Contributors TD and LB conceptualised the study. All authors contributed to the design of the study. TD analysed the data. All authors contributed to the writing of the original draft of the manuscript. All authors contributed to the development of the manuscript and read and approved the final version. The corresponding author attests that all listed authors meet authorship criteria and that no others meeting the criteria have been omitted.

Funding The authors have not declared a specific grant for this research from any funding agency in the public, commercial or not-for-profit sectors.

Competing interests None declared.

Patient consent for publication Not required.

Ethics approval The DHS receive Ugandan government permission, use informed consent and assure respondents of confidentiality. The DHS received institutional review centrally (ICF International). Approval for our use of data was sought and received from the DHS Programme.

Provenance and peer review Not commissioned; externally peer reviewed.

Data availability statement Data are available in a public, open access repository. The data included in this study is non-identifiable, anonymised data from the publicly available DHS data sets from Uganda. The data sets were analysed during this study and all analysis are presented in the main article and online supplemental material. All data analysis is held by the submitting author (TD ORCID identifier https://orcid.org/0000-0003-1326-5107).

Supplemental material This content has been supplied by the author(s). It has not been vetted by BMJ Publishing Group Limited (BMJ) and may not have been peer-reviewed. Any opinions or recommendations discussed are solely those of the author(s) and are not endorsed by BMJ. BMJ disclaims all liability and responsibility arising from any reliance placed on the content. Where the content includes any translated material, BMJ does not warrant the accuracy and reliability of the translations (including but not limited to local regulations, clinical guidelines, terminology, drug names and drug dosages), and is not responsible for any error and/or omissions arising from translation and adaptation or otherwise.

Open access This is an open access article distributed in accordance with the Creative Commons Attribution 4.0 Unported (CC BY 4.0) license, which permits others to copy, redistribute, remix, transform and build upon this work for any purpose, provided the original work is properly cited, a link to the licence is given, and indication of whether changes were made. See: https://creativecommons.org/ licenses/by/4.0/.

\section{ORCID iD}

Teesta Dey http://orcid.org/0000-0003-1326-5107 


\section{REFERENCES}

1 WHO. Trends in maternal mortality 2000 to 2017: estimates by who, UNICEF, UNFPA, world bank group and the United nations population division. Geneva: World Health Organization, 2019.

2 Hug L, Alexander M, You D, et al. National, regional, and global levels and trends in neonatal mortality between 1990 and 2017, with scenario-based projections to 2030: a systematic analysis. Lancet Glob Health 2019;7:e710-20.

3 UN. The sustainable development goals report 2020. Geneva: United Nations, 2020. https://unstats.un.org/sdgs/report/2020/TheSustainable-Development-Goals-Report-2020.pdf

4 UN. Progress towards the sustainable development goals report of the Secretary-General 2019. Geneva: United Nations, 2019. https:// sustainabledevelopment.un.org/content/documents/24978Report of_the_SG_on_SDG_Progress_2019.pdf

5 Uganda Bureau of Statistics - UBOS and ICF. 2018. Uganda demographic and health survey. Kampala, Uganda: UBOS and ICF, 2016. http://dhsprogram.com/pubs/pdf/FR333/FR333.pdf

6 Benova L, Dennis ML, Lange IL, et al. Two decades of antenatal and delivery care in Uganda: a cross-sectional study using demographic and health surveys. BMC Health Serv Res 2018;18:758.

7 Victora CG, Requejo JH, Barros AJD, et al. Countdown to 2015: a decade of tracking progress for maternal, newborn, and child survival. Lancet 2016;387:2049-59.

8 Sacks E, Langlois Étienne V. Postnatal care: increasing coverage, equity, and quality. Lancet Glob Health 2016;4:e442-3.

9 Ronsmans C, Graham WJ, Lancet Maternal Survival Series steering group. Maternal mortality: who, when, where, and why. Lancet 2006;368:1189-200.

10 WHO. Technical consultation on postpartum and postnatal care. Geneva: WHO, 2010. https://apps.who.int/iris/bitstream/handle/ 10665/70432/WHO_MPS_10.03_eng.pdf?sequence $=1$

11 Khan KS, Wojdyla D, Say L, et al. Who analysis of causes of maternal death: a systematic review. Lancet 2006;367:1066-74.

12 Birko S, Dove ES, Özdemir V. Evaluation of nine consensus indices in Delphi foresight research and their dependency on Delphi survey characteristics: a simulation study and debate on Delphi design and interpretation. PLoS One 2015;10:e0135162.

13 GBD 2013 Mortality and Causes of Death Collaborators. Global, regional, and national age-sex specific all-cause and causespecific mortality for 240 causes of death, 1990-2013: a systematic analysis for the global burden of disease study 2013. Lancet 2015;385:117-71.

14 Campbell OMR, Graham WJ, Lancet Maternal Survival Series steering group. Strategies for reducing maternal mortality: getting on with what works. Lancet 2006;368:1284-99.

15 WHO. Who recommendations on postnatal care of the mother and newborn. Geneva: WHO, 2019. https://apps.who.int/iris/bitstream/ handle/10665/97603/9789241506649 eng.pdf?sequence=1

16 Campbell OMR, Cegolon L, Macleod $\bar{D}$, et al. Length of stay after childbirth in 92 countries and associated factors in 30 low- and middle-income countries: compilation of reported data and a crosssectional analysis from nationally representative surveys. PLoS Med 2016;13:e1001972.

17 Benova L, Owolabi O, Radovich E, et al. Provision of postpartum care to women giving birth in health facilities in sub-Saharan Africa: a cross-sectional study using demographic and health survey data from 33 countries. PLoS Med 2019;16:e1002943.

18 Munabi-Babigumira S, Nabudere H, Asiimwe D, et al. Implementing the skilled birth attendance strategy in Uganda: a policy analysis. BMC Health Serv Res 2019;19:655.

19 Konde-Lule J, Gitta SN, Lindfors A, et al. Private and public health care in rural areas of Uganda. BMC Int Health Hum Rights 2010;10:29.

20 Parkhurst JO, Penn-Kekana L, Blaauw D, et al. Health systems factors influencing maternal health services: a four-country comparison. Health Policy 2005;73:127-38.

21 Wallace LJ, Kapiriri L. Priority setting for maternal, newborn and child health in Uganda: a qualitative study evaluating actual practice. BMC Health Serv Res 2019;19:465.

22 The Republic of Ugandan Ministry of Health. National guidelines for management of common conditions Uganda clinical guidelines 2016.

23 de Graft-Johnson J, Vesel L, Rosen HE, et al. Cross-Sectional observational assessment of quality of newborn care immediately after birth in health facilities across six sub-Saharan African countries. BMJ Open 2017;7:e014680.
24 Duysburgh E, Kerstens B, Kouanda S, et al. Opportunities to improve postpartum care for mothers and infants: design of contextspecific packages of postpartum interventions in rural districts in four sub-Saharan African countries. BMC Pregnancy Childbirth 2015;15:131.

25 Belemsaga DY, Kouanda S, Goujon A, et al. A review of factors associated with the utilization of healthcare services and strategies for improving postpartum care in Africa. Afrika Focus 2015;28:83-105.

26 Countdown to 2030 Collaboration. Countdown to 2030: tracking progress towards universal coverage for reproductive, maternal, newborn, and child health. Lancet 2018;391:1538-48.

27 Souza JP, Gülmezoglu AM, Vogel J, et al. Moving beyond essential interventions for reduction of maternal mortality (the who multicountry survey on maternal and newborn health): a crosssectional study. Lancet 2013;381:1747-55.

28 Ndugga P, Namiyonga NK, Sebuwufu D, ogratious SD. Determinants of early postnatal care attendance: analysis of the 2016 Uganda demographic and health survey. BMC Pregnancy Childbirth 2020;20:163.

29 Dhaher E, Mikolajczyk RT, Maxwell AE, et al. Factors associated with lack of postnatal care among Palestinian women: a cross-sectional study of three clinics in the West bank. BMC Pregnancy Childbirth 2008;8:26.

30 Moran AC, Kerber K, Sitrin D, et al. Measuring coverage in MNCH: indicators for global tracking of newborn care. PLoS Med 2013;10:e1001415

31 Weeks A, Lavender T, Nazziwa E, et al. Personal accounts of 'near-miss' maternal mortalities in Kampala, Uganda. BJOG 2005;112:1302-7.

32 Sakala B, Chirwa E. An evidence-based policy brief: improving the quality of postnatal care in mothers 48 hours after childbirth. Malawi Med J 2019;31:164-8.

33 Izudi J, Amongin D. Use of early postnatal care among postpartum women in eastern Uganda. Int J Gynaecol Obstet 2015;129:161-4.

34 Sacks E, Masvawure TB, Atuyambe LM, et al. Postnatal care experiences and barriers to care utilization for Home- and FacilityDelivered newborns in Uganda and Zambia. Matern Child Health J 2017;21:599-606.

35 Sacks E, Kinney MV. Respectful maternal and newborn care: building a common agenda. Reprod Health 2015;12:46.

36 Ntambue AM, Malonga FK, Dramaix-Wilmet M, et al. Commercialization of obstetric and neonatal care in the Democratic Republic of the Congo: a study of the variability in user fees in Lubumbashi, 2014. PLoS One 2018;13:e0205082.

37 Kim ET, Singh K, Weiss W. Maternal postnatal care in Bangladesh: a closer look at specific content and coverage by different types of providers. J Glob Health Rep 2019;3:e2019004.

38 Sandall J, Tribe RM, Avery L, et al. Short-Term and long-term effects of caesarean section on the health of women and children. Lancet 2018;392:1349-57

39 Bishop D, Dyer RA, Maswime S, et al. Maternal and neonatal outcomes after caesarean delivery in the African surgical outcomes study: a 7-day prospective observational cohort study. Lancet Glob Health 2019;7:e513-22.

40 Tessema ZT, Yazachew L, Tesema GA, et al. Determinants of postnatal care utilization in sub-Saharan Africa: a meta and multilevel analysis of data from 36 sub-Saharan countries. Ital J Pediatr 2020;46:175.

41 Adams YJ, Smith BA. Integrative review of factors that affect the use of postpartum care services in developing countries. J Obstet Gynecol Neonatal Nurs 2018;47:371-84.

42 Fekadu GA, Ambaw F, Kidanie SA. Facility delivery and postnatal care services use among mothers who attended four or more antenatal care visits in Ethiopia: further analysis of the 2016 demographic and health survey. BMC Pregnancy Childbirth 2019;19:64

43 Bhutta ZA, Das JK, Bahl R, et al. Can available interventions end preventable deaths in mothers, newborn babies, and stillbirths, and at what cost? Lancet 2014;384:347-70

44 Amouzou A, Mehra V, Carvajal-Aguirre L, et al. Measuring postnata care contacts for mothers and newborns: an analysis of data from the MICs and DHS surveys. J Glob Health 2017;7:020502.

45 McCarthy KJ, Blanc AK, Warren C. Validating women's reports of antenatal and postnatal care received in Bangladesh, Cambodia and Kenya. BMJ Glob Heal 2020;5:2133.

46 Amouzou A, Hazel E, Vaz L, et al. Discordance in postnatal care between mothers and newborns: measurement artifact or missed opportunity? J Glob Health 2020;10. 